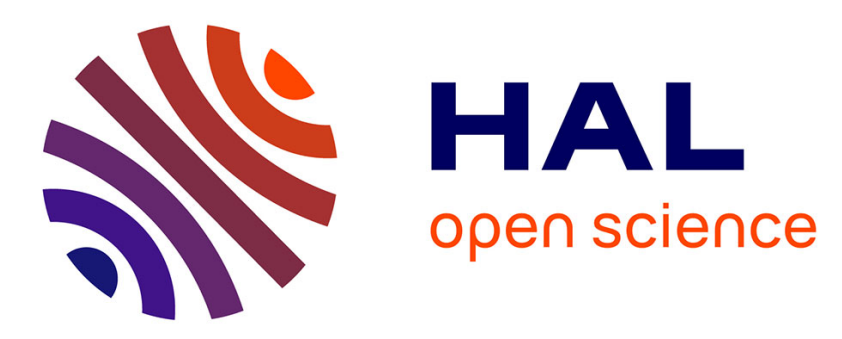

\title{
New Requirement Analysis Approach for Cyber-Physical Systems in an Intralogistics Use Case
}

Günther Schuh, Anne Bernardy, Violett Zeller, Volker Stich

\section{To cite this version:}

Günther Schuh, Anne Bernardy, Violett Zeller, Volker Stich. New Requirement Analysis Approach for Cyber-Physical Systems in an Intralogistics Use Case. 18th Working Conference on Virtual Enterprises (PROVE), Sep 2017, Vicenza, Italy. pp.149-156, 10.1007/978-3-319-65151-4_14 . hal-01674853

\section{HAL Id: hal-01674853 https://hal.inria.fr/hal-01674853}

Submitted on 3 Jan 2018

HAL is a multi-disciplinary open access archive for the deposit and dissemination of scientific research documents, whether they are published or not. The documents may come from teaching and research institutions in France or abroad, or from public or private research centers.
L'archive ouverte pluridisciplinaire HAL, est destinée au dépôt et à la diffusion de documents scientifiques de niveau recherche, publiés ou non, émanant des établissements d'enseignement et de recherche français ou étrangers, des laboratoires publics ou privés.

\section{(c)(1)}

Distributed under a Creative Commons Attribution| 4.0 International License 


\title{
New Requirement Analysis Approach for Cyber-Physical Systems in an Intralogistics Use Case
}

\author{
Günther Schuh, Anne Bernardy, Violett Zeller and Volker Stich \\ FIR Institute for Industrial Management, \\ RWTH Aachen University, Campus-Boulevard 55, 52074 \\ Aachen, Germany \\ $\{$ Günther.Schuh, Anne.Bernardy, Violett.Zeller, \\ Volker.Stich\}@fir.rwth-aachen.de
}

\begin{abstract}
Nowadays, cyber physical systems support the improvement of efficiency in intralogistics by controlling and manipulating the production and logistic environment autonomously. Due to the complexity of the individual production processes, designing suitable cyber-physical systems based on their existing production environment is a challenge for companies. This paper presents a new methodology on how to design cyber-physical systems conceptually to suit an individual production environment. Compared to existing design approaches, this methodology matches immediately the required functions to existing information and communication technology's components insisting on the neutral assimilation of requirements. Therefore, the requirement specification asks for needed functions in relating to offered functions of information and communication technology (ICT) components. The paper focusses the use case of implementing a cutting-edge mobile network technology into an existing tracking and tracing process
\end{abstract}

Keywords: CPS, Matching, Collaboration, Requirements

\section{Introduction}

Nowadays, companies pursue the implementation of intelligent systems in their production to keep up with the changing demands towards the flexible production of tomorrow. Through a dedicated use of information technologies like monitoring systems to supervise the production status of orders and material flows, the production status can be communicated and visualized in real-time, and an optimized production line can be analysed per order [1]. These potentials are essential factors for small and medium-sized enterprises (SMEs) to maintain their competitiveness.

However, most companies are limited in time and financial resources to integrate CPS into the intralogistics of their production. One major challenge is the conceptual design and the use of information technologies due to the constantly growing market of CPS. Furthermore, the benefit and deployment depend on many factors as individual required functionalities so that SMEs need to rely on external expertise for inte- 
gration $[1,2]$

This complexity is caused by the unclear definition how to design CPS[3,4]. Historically CPS are an evolution of embedded systems, so that existing design methods are based on system engineering methodologies. Using existing modelling approaches requires the configuration of process models [4-6] but do not support the choice of suitable information and communication technologies (ICT). In addition, the design of complex CPSs requires a comprehensive knowledge of these production processes beneath the knowledge of system engineering, which is usually only known by the user company itself. Since the market for information and communication technologies grows exponentially, a specialized knowledge of these technologies is needed to ensure the best possible solutions for a CPS concept and realization. The process of integrating individual CPSs in manufacturing companies is accompanied by the challenge of knowing and taking into account all relevant interfaces in advance[7].

Hence, this paper proposes a new method to introduce CPS. Since one common use case for CPS is to connect a tracking and tracing system, this use case serves as an example to illustrate the provided approach explaining how to choose systematically information and communicating systems in the intralogistics to transform it to a CPS.

\section{State of the Art}

These days, the tracking and tracing of products in the intralogistics is essential for different reasons. On the one hand, products in the reclamation allow the interference to the reasons of quality lack. On the other hand, tracking and tracing orders and material helps to point out difficulties of the production and logistic processes. The global logistics use standard identification systems, that can register their status autonomously and which are standardized like the EPCIS, for about 20 years [8]. In contrast, tracking and tracing systems for the intralogistics are mostly insulated applications referring to the individual company [9]. Due to the changing requirements toward the productions effectivity caused by the digitalization, tracking and tracing systems need to get connected to the industrial internet as well as the material and orders of the company. Therefore, the tracking and tracing system needs to be transformed into a cyber-physical system.

The conception of a CPS however requires a common definition for all stakeholders, but no commonly acknowledged definition has been established so far [10]. To develop the approach to match applicant's requirements and technology functions, the FIR INSTITUTE FOR INDUSTRIAL MANAGEMENT invented a functional definition based on the definitions of [11-13], which presents six main functions in a CPS [14].

Currently, the only designing and modelling methods for CPS refer to configurations of the chosen components in a simulation environment, e.g. in Modelica, Matlab or Simulink $[3,4,15]$. Since these tools require user skills to simulate the interdependencies between already selected components, they neither support the selection of technologies nor are they suitable for the use by untrained system designers. In addition, they don't involve the applicant into the designing process and do not support requirement engineering approaches to ensure an entire, solution-neutral requirement 
recording. The selection of the technologies needs to factor new, upcoming ICT because the implementation process of a cyber-physical system takes up to two years in average [16-18]. Screening the ICT market is moreover incessant to ensure the selection of a sustainable and effective technology portfolio.

For a proper decision-making, the alignment between applicant's requirements and technology provided functions needs to be supported by a cost-value-analysis of given matching results between problems and solutions. The following section will describe the foundation of the matching methodology.

\section{Scientific Approach - The Matching Method Applied to Tracking and Tracing}

As mentioned before, a CPS contains technologies from the cyber and the physical world. Implemented to tracking and tracing systems, they enable more flexibility and environment independence when networking transmission technologies are used to globally connect the tracking and tracing system. Concerning the example use case in this paper of the connected material tracking in a production, the desired cyberphysical system needs sensors to identify the location of the material. Suitable technologies are e.g. Auto-ID technologies such as RFID or barcode systems. Furthermore, the identification has to be connected to the central local or global controlling system.
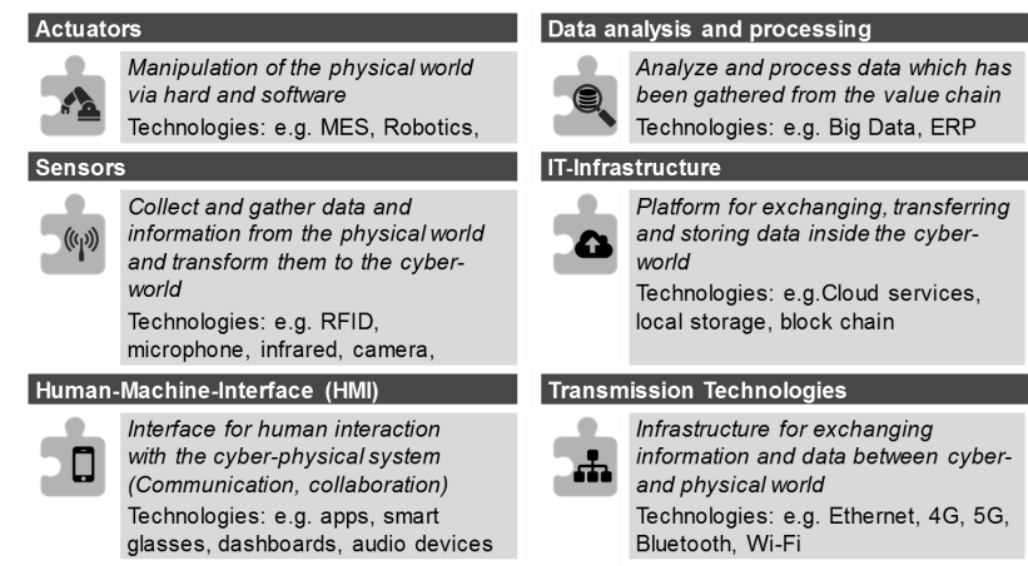

Fig. 1: The six technology clusters and their tasks

Hence, transmission technologies have to be used like Bluetooth or mobile connectivity. To fulfil the aim of the tracking and tracing, the data needs to be firstly transformed by tools like e.g. diagrams and then displayed e.g. on a smart device or a terminal. Finally, the cyber-physical system contains an actuator like e.g. a robot which can interact due to implemented logics. If there is no autonomic, technical system to 
interact, there is at least a human to react to the events during the production process. Finally, the CPS needs a stable IT infrastructure as a backbone. This example illustrates the different functions a CPS has to fulfil. Based on case research, the FIR Institute for Industrial Management at the Aachen University formed six technology clusters to categorize information- and communication systems [14]. Fig. 1 gives an overview of the definitions and example technologies for the six technology clusters developed at FIR in Aachen. They were conceived to increase accuracy in describing CPS technologies, allowing for a more systematic approach towards categorizing CPSs. As shown in Fig. 1 the technology clusters are:

- Actuators: Actuators represent the means of a CPS to interact and manipulate the physical world via hard- and software applications. On the one hand, this can be a hardware like a robot or a motor control. On the other hand, software like a MES (manufacturing execution system) can control production systems and change its setup.

- Sensors: Sensors build the antagonist to the actuators cluster. The aim of sensor technologies is the generation of data. Concerning tracking and tracing use cases, sensors especially assimilate localization and identification data. Auto-ID sensors e.g. like RFID-chips support the detection of the location of an item or identification the product being handled, as well as camera systems that automatically recognize the positioning of the work piece and which are monitoring the piece's quality are examples for sensors in the industrial context.

- Human-Machine-Interface (HMI): Human-Machine-Interfaces support the decision support. The visualization of aggregated data is a central aim of the technologies referring to this cluster. Corresponding to the tracking and tracing systems, HMI can appear in the form of a dashboard giving a real-time overview of material and order flows, and can uncover material, information or orders stacks. Theses dashboards can be displayed e.g. on smart devices (smartphone, table) or on BDEterminals. Other interaction possibilities are realized via speech (e.g. pick-byvoice).

- Data Analysis and processing: The raw data needs to be analysed referring to an individual task. Referring to the tracking and tracing system, methods like deep learning build the basic to reduce order or material stockings automatically. Artificial intelligences (AIs) can predict shifts in machine occupancy and change the job distribution inside the production system to re-establish an equilibrium on their own.

- IT infrastructure: Essentially, all the data assimilation, processing and transfer refers to a stable IT infrastructure. The aim of the technologies of this cluster is to ensure the data, information and knowledge in defined storages like central servers or in the decentral cloud to keep it retrievable at any time. Corresponding to the connected tracking and tracing systems, the data needs to be stored and available for different stakeholders like the production manager to interact if any flow is stacked or the customer supports to calculate the delivery time. E.g. cloud technologies offer the new flexibility to scale the IT infrastructure according to current requirements. However, cloud services decrease the control over the processed data.

- Transmission Technologies: Finally, the transmission of data between admission localization and users need to be realized. Transmission technologies such as mo- 
bile communication, Wireless LAN, Ethernet or bus-systems like ProfiNetC provide the technical infrastructure to exchange data and information within the different agents inside the cyber-physical system. In respect to tracking and tracing systems, the requirement towards more flexible ways of data transmission increases so that wireless communication technologies such as $4 \mathrm{G}, 5 \mathrm{G}$, and Wireless LAN gain in importance. Depending on the environment, their reliability and their security function lack the requirement so that Ethernet or Fieldbus are the preferable options.

To match the right technologies to individual requirements, a systematical alignment approach is obligatory. Since available technologies of the market can contain several functions of different technology clusters, the matching needs to consider functional overlapping to avoid redundant technology suggestions. Therefore, for all clusters morphologies are designed with categories, attributes and characteristics.

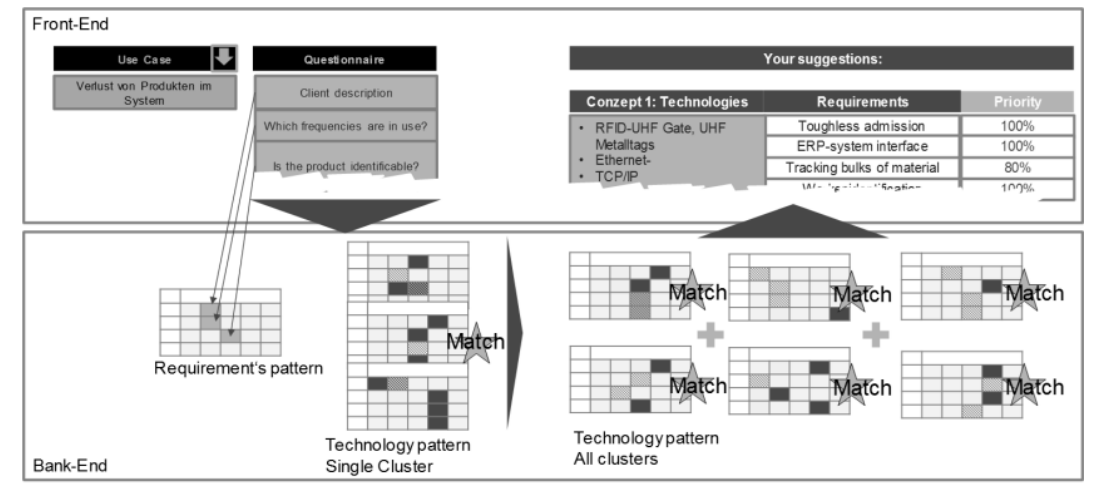

Fig. 2: Example of the matchmaker

The morphologies serve as a pattern to categorize technologies. If a technology is sorted into a technology cluster, it creates an own pattern which later on can be compared to the requirement pattern (see Fig. 2). Every technology assigns for at least one of the clusters. New developments regarding e.g. RFID systems are covering multiple technology cluster aims. They are sorted into several clusters and the matching algorithm proves the redundancy of the functionalities. In relation to the tracking and tracing use case, typical technologies like identification and localization systems are defined by the physical measurement task, the data transmission quality, the existing clients to run IT systems in general and the desired interaction like visualization via a touchable display of the humans.

Theses morphologies form the structure for the systematic requirement assimilation presented in section 0 in this paper and shape the framework of the matchmaking algorithm. Based on the typologies for both the requirements and the technologies, the matching algorithm can then identify the best matches for requirements and solutions. This means that the requirements need to be assimilated into the same kind of pattern like the technologies are clustered. The applicant has to fulfil a questionnaire matching the categories, attributes and characteristics with requirements and to prioritize these requirements by a paired comparison. The ranking decides the alignment process in which or Hence, every question of that requirement guidance is a translation from an available function to a customer need. Mostly, one question asks for one 
attribute. Since the six clusters contain more than 15 characteristics per cluster with at least two attributes, the applicant needs to answer more than 200 questions. To minimize the effort for the applicant, the questionnaire fades out questions corresponding to answered ones. The fulfilled questionnaire forms than the requirement pattern. The process in the configurator to extract the requirement pattern efficiently is explained in the next section.

\section{Requirement Extraction}

For the requirement extraction, three overhead-use-case-types are given by the magic triangle of logistic problems [19]. The triangle shows that logistic problems can transferred to an initial issue such as:

- A quality process improvement $\rightarrow$ getting better

- An efficiency increase $\rightarrow$ getting faster

- A cost decrease $\rightarrow$ getting less expensive

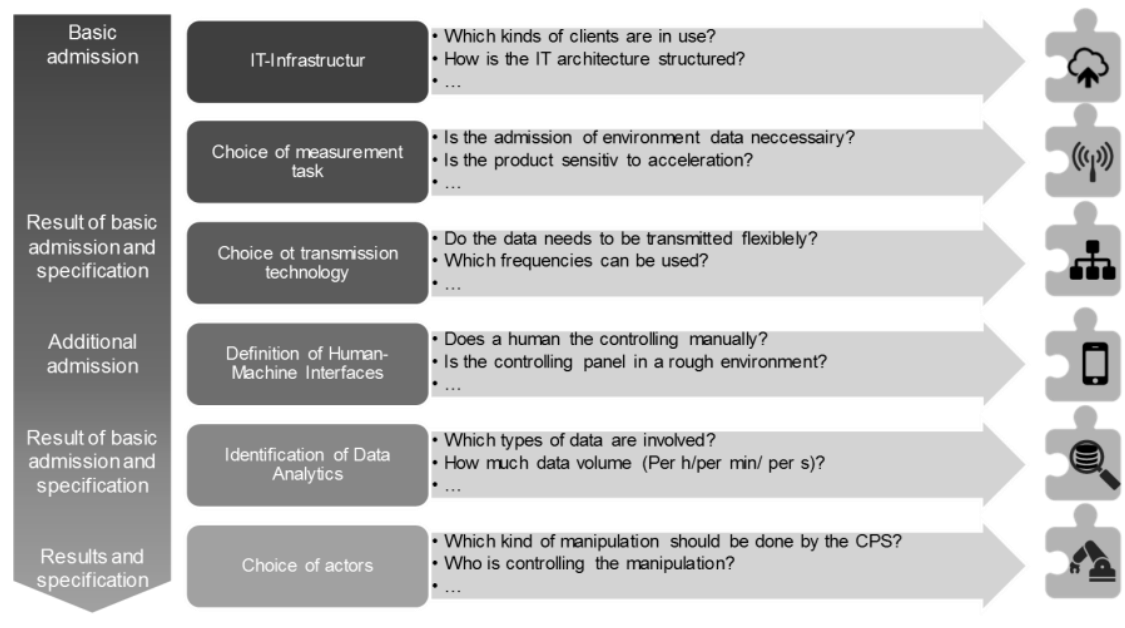

Fig. 3: The questionnaire process

The three types of use-cases require different pre-sets of combinations of attributes of the technology clusters and therefore different pre-sets of characteristics. Nevertheless, two of the technology clusters are essential for every use-case-type because of the definition of a cyber-physical system: the transmission technologies to transfer the data of the data sources to a central or decentral data store, which is part of the $I T$ infrastructure.

The first use-case-type Quality requires e.g. all kinds of proving and checking processes as well as measurement processes. Problems of quality management in the intralogistics are e.g. producing lots of waste or certify critical products. Stage-Gate processes are known in the quality management to decide the status of a product. The second use-case-type Time requires support systems and automation systems. The pre-set questions focus on Human-Machine-Interfaces and the possibilities to assist 
the worker with wearables.

Talking about industrie 4.0, this use-case-type includes questions about flexibility and an efficient one-piece production [20]. The third use-case-type costs brings into focus the problems like too high costs. Compared to the use-case-type time material flows are analyzed and have to be improved. The recorded IT infrastructure is essential to detect redundant or unused systems. The data analysis need to be specified by the individual applicant's problem so that the questionnaire is just reduced to typical visualization tasks like the overview of e.g. correlations between environment data (e.g. temperature, humidity) and failures of the products.

\section{Summary and Outlook}

The matchmaking supports the networking of technology suppliers and applicants and is realized by an online platform; via whose Web front the requirements are recorded. For an efficient determination of requirements, the user selects a problem description from a list of reference application cases, which corresponds to his individual problem situation (see Fig. 2). The pre-selection limits the following questionnaire to a selection of relevant questions. The structure of the questionnaire provides a continuous containment of the questions so that the effort of the filling is reduced to a minimum for the applicant.

Six functional technology clusters built the framework for both, the requirement assimilation and the technology sorting. Hence, the requirement recording is structured and implemented in a way that gradually limits the number of possible technologies to the compatible and application-specific components from the existing framework conditions and the specification of the optimization target.

The questionnaire asserts a solution-neutral requirement assessment to ensure that users are offered the most efficient and effective solution. The CPS matchmaker compares the requirements profile with its broad portfolio of technologies. The solutionneutral formulation prevents companies from using well-known technologies without knowing all the technologies that functionally fulfill the required task.

Currently, the CPS matchmaker is in the process of recording and validating application cases as well as technologies and their providers. According to the project sponsored by the Leitmarkt.IKT agency and the EFRE, the CPS matchmaker will be completed as an online platform by the end of 2018 and will be continually validated by summer 2019. In addition to the application-oriented reference application cases of the application partners, further applications for test purposes may be included in the case of interest. Current information can be viewed at: cyberKMU.de

\section{Acknowledgement}

This work has been funded by the Leitmarkt.NRW program of the European Federation R E cooperating with the federation of North-Rhine-Westphalia (NRW) while the project "cyberKMU". The authors wish to acknowledge the EFRE and NRW for their support. 


\section{References}

[1] Frey, C., Heinzmann, M., Niggemann, O., et al.: 'IKT in der Fabrik der Zukunft', atp edition, 2014, 04, (56), pp. 42-53

[2] Matt, D., Rauch, E., eds.: 'Chancen zur Bewältigung des Fachkraeftemangels in KMU' (2014)

[3] Akkaya, I., Derler, P., Emoto, S., Lee, E.A.: 'Systems Engineering for Industrial CyberPhysical Systems Using Aspects', Proc. IEEE, 2016, 104, (5), pp. 997-1012

[4] Derler, P., Lee, E.A., Vincentelli, A.S.: 'Modeling Cyber-Physical Systems', Proc. IEEE, 2012, 100, (1), pp. 13-28

[5] Baum, G., Borcherding, H., Broy, M., et al.: 'Industrie 4.0: Beherrschung der industriellen Komplexität mit SysLM' (Springer-Vieweg, Berlin, 2013)

[6] Akkaya, I., Derler, P., Emoto, S., Lee, E.A.: 'Systems Engineering for Industrial CyberPhysical Systems Using Aspects', Proc. IEEE, 2016, 104, (5), pp. 997-1012

[7] Acatech, ed.: 'Cyber-Physical Systems: Innovationsmotor für Mobilität, Gesundheit, Energie und Produktion' (2011)

[8] Kropp, S.: 'Entwicklung eines generischen Ereignismodells als Grundlage der Produktionsregelung' (Aachen, 2015)

[9] Bauernhansl, T.: 'Industrie 4.0 in Produktion, Automatisierung und Logistik: Anwendung, Technologien und Migration' (Springer Vieweg, Wiesbaden, 2014)

[10] Bettenhausen, K.D., Kowalewski, S.: 'Cyber-Physical Systems: Chancen und Nutzen aus Sicht der Automation', 2013

[11] Lee, E.A.: 'Cyber Physical Systems: Design Challenges', Computer Society, 2008, pp. 363-369

[12] National Science Foundation: 'Cyber-Physical Systems (CPS)' (2010)

[13] National Science Foundation: 'Cyber-Physical Systems (CPS)' (2016)

[14] Jordan, F., Bernardy, A., Stich, V., eds.: 'Requirements-based matching approach to configurate cyber-physical systems for SMEs' (2017)

[15] Lee, J., Bagheri, B., Kao, H.-A.: 'A Cyber-Physical Systems architecture for Industry 4.0based manufacturing systems', Manufacturing Letters, 2014, 3, pp. 18-23

[16] Stich, V., Deindl, M., Jordan, F., Maecker, L., Weber, F.: 'Studie - Cyber physial Systems in der Produktionspraxis' (Wuppertal, 2015)

[17] Lee, E.A.: 'The Past, Present and Future of CPS: A focus on Models', Sensors, 2015, 15, (3), pp. 4837-4869

[18] Stich, V., Jordan, F., Birkmeier, M., Oflazgil, K., Reschke, J., Diews, A.: 'Big Data Technology for Resilient Failure Management in Production Systems', in Umeda, S., Nakano, M., Mizuyama, H., Hibino, N., Kiritsis, D., Cieminski, G. von (Eds.): 'Advances in production management systems: Innovative production management towards sustainable growth : IFIP WG 5.7 International Conference, APMS 2015, Tokyo, Japan, September 7-9, 2015, Proceedings' (Springer, Cham, 2015), pp. 447-454

[19] Pfeifer, T., Schmitt, R.: 'Qualitätsmanagement: Strategien - Methoden - Techniken' (Hanser, München, 2010, 4th edn.)

[20] Kagermann, H., Gausemeier, J., Anderl, R., Schuh, G., Wahlster, W., eds.: 'Industrie 4.0 im globalen Kontext:: Strategien derZusammenarbeit mit internationalen Partnern' (Herbert Utz Verlag, München, 2016) 